\title{
1. Migration and economic development: an introduction and synopsis
}

Robert E.B. Lucas

Much of the early interest in the economics of migration in developing countries focused on internal movements, especially the transfers of population from rural to urban settings. More recently attention has shifted toward international migration instead. This increased focus on international migration among analysts has been mirrored at the political level, heightened by changing realities: by the rise in immigration into the "moredeveloped' regions, where the migrant stock now exceeds 10 percent of the population, including in large parts of Europe that traditionally saw net emigration; by the dramatic rise in recorded remittances in the last decade, reaching over $\$ 500$ billion globally, of which more than $\$ 400$ billion are going to the developing countries; by the expanding 'brain drain' from lower- to higher-income countries; and by security concerns surrounding international terrorism since 2001.

Migration and economic development are mutually linked. Development may impact migration and vice versa, though the signs of causal links in both directions remain a matter of some dispute, as we shall see in the course of this volume. The various chapters chart the state of thinking on a number of key facets of the reciprocal links between migration and development, but also, in several instances, extend our frontiers of understanding with fresh evidence.

Empirical research into the migration-development nexus has been, and continues to be, both shaped and hampered by the availability of migration data. Aggregate data on immigration into most of the OECD countries have been reported for some time now, though with little detail on the composition of the migrant stocks; data on South-South migration are far more scant, as is information on some of the large population movements into high-income, non-OECD countries, including those of the Persian Gulf. Chapter 2 examines where data collection on population movements stands. Gero Carletto and co-authors describe the limitations and strengths of the main sources of data currently available, at both the micro and aggregate levels; the conceptual and definitional issues that arise in assembling migration data; and how the extant data may generally be used to address some of the key areas of policy concern. This account 
provides an important backdrop to the remaining chapters in the volume, each of which draws on portions of the data described.

Migration is sometimes depicted as a temporary phenomenon, a feature of adjustment to disequilibrium that will pass. It is not. The great migrations of mankind stretch over our entire history: the initial migration of Homo sapiens out of Africa perhaps 70000 years ago certainly transformed our world; the exodus of Jews out of Egypt and the Barbarian invasions of the Roman Empire; the Arabic and Atlantic trade in slaves; the mass migrations from Europe to North America; the consequences of partitioning India; and more recently the huge internal movements within China, to name but a few. In his chapter, Bob Margo takes a look at the nature and consequences of these mass flows through the lens of the USA before World War I, a lens that offers a broad and intriguing perspective. The evidence that Bob amasses indicates, inter alia: the role that the Age of Mass Migration played in economic convergence between North America and Europe; that the USA was never a melting pot, even during the nineteenth century; and how the history of slavery laid the foundations for another great migration, of African Americans departing the South for the industrial North of the USA.

Whereas North America and Australasia have been important magnets attracting large numbers of migrants over the last couple of centuries, Europe has never seen itself as a key migrant destination. Indeed, Europe provided many of the emigrants to the new lands. But this pattern has shifted; some European states now have a larger fraction of foreign-born residents than does the USA. Africa's population is projected to rise rapidly while that of parts of Europe may contract. Combined with the proximity of the two continents and the growing gap between their income levels, increased migration to Europe might well be anticipated. Deaths of migrants attempting boat journeys to reach Europe from Africa are already common. In some of the European states that have transitioned to become destinations of net immigration, an interest has been spawned in co-development, promoting economic progress of the poorer parts of the world, or using development aid as a bargaining tool, in the belief that emigration pressures will thus be diminished. The next three chapters in this volume address related portions of this strategy.

Christopher Parsons and Alan Winters focus on the links between trade, aid and migration. The trade portion of their contribution considers three main aspects: the implications and limitations of the HeckscherOhlin-Samuelson theorem, leading to factor price equalization with trade and migration as perfect substitutes; the theoretical literature on migration as a source of information and contract enforcement, leading to trade expansion; and the empirical literature, largely in the context of 
gravity models, of migration as a determinant of bilateral trade flows. Chris and Alan also summarize the much smaller literature on the link from aid to migration. Throughout, an underlying theme in their analysis is whether observed links can be identified as causal and where the gaps lie in the extant analyses. In concluding, Chris and Alan place the trade-aidmigration nexus within the context of co-development policies of which they are quite critical.

In her chapter, Flore Gubert shows us why, offering a critical perspective on the realities of European attempts to influence migration through development of the countries of origin. Flore details both the history of co-development efforts and the more recent forms that these have taken among the major European Union partners. What emerges is a substantial gap between the narrative and the realities of these policies. Flore then continues to examine various initiatives to involve diaspora in the development of their home states, including attempts to stimulate remittances through formal channels, to redirect remittances toward productive investments, and to facilitate skill and knowledge transfers. Harnessing remittances for development has also become a focus for many of the high emigration states, though Flore exposes both the weaknesses and inappropriate intent of much of this effort. This chapter appears to be the first comprehensive review of these varied efforts. Flore is clearly skeptical of many of the realities of these policies but, nonetheless, concludes by distilling some of the necessary conditions for their success.

The presumption underlying the co-development strategies is that improving economic conditions in the lower-income countries will dissipate pressures to emigrate. In his chapter, Michael Clemens summarizes 45 years of discussion and evidence to the contrary. The counter-argument is that emigration initially rises with increments to income at home, eventually turning downward to generate what is sometimes called a migration hump or transition. Michael itemizes and evaluates six arguments that have been hypothesized to underlie such a pattern of migration. The prior evidence on whether a turning point exists is mixed, in the context of both aggregate and micro data. The results vary with the data sources analyzed, tending to reveal a parabolic form more often in the crosssection than over time, and Michael considers why this may be the case. Adopting the latest, aggregate, panel data set, Michael finds a clear and significant 'hump' in both the stocks and flows of international migrants, lending substantial support to some of the reservations expressed about co-development strategies both by Chris Parsons and Alan Winters and by Flore Gubert in their respective chapters.

Circular migration of less-skilled workers is often touted as one of the most effective migration patterns for relieving poverty in the countries 
of origin. Remittances from less-skilled workers tend to go to poorer households; the intent or requirement to return home may enhance these transfer levels; and the departure of less-skilled workers may improve the labor-market lot of those remaining at home. Among host states, permanent entry of less-skilled workers is rarely welcomed, though seasonal workers and other temporary labor schemes are quite common. Circular migration may thus be in the interest of both home and host states, though perhaps not in the interest of the migrants themselves. This last caveat often renders the temporary nature of migrant-worker programs difficult to enforce, and Milton Friedman's more general statement is often paraphrased as 'Nothing is so permanent as a temporary migration program.'

The next group of three chapters in this volume addresses different aspects of temporary worker programs and the migration of less-skilled labor. John Gibson and David McKenzie note that almost all OECD countries have some form of seasonal worker programs, but that several of these are being cut back or eliminated. Against this backdrop, John and David take a careful look at New Zealand's Recognised Seasonal Employer program launched in 2007. They conclude that the program has been a triple winner: the migrant workers certainly gain from the experience; there is no evidence that New Zealand workers are displaced and employers gain access to foreign workers who prove more productive than locals, a productivity gap that increases with return visits; third, evidence is amassed showing at least small spillover benefits to locals in the origin countries. In the context of ongoing and politically charged debates over temporary worker programs the evidence in this chapter offers important insights.

Jonathan Crush paints a fascinating picture of the shifting balances in South Africa's migration and labor markets as the country has transitioned from the apartheid era to rule by universal franchise. Before 1994, immigration into South Africa was tightly controlled and bimodal. Europeans were welcomed as settlers; limited numbers of Africans were permitted temporary entry as cheap labor for the mines and other sectors. Jonathan documents the complexities of the transition from this legacy to the new era. After more than a century of reliance on foreign labor in South Africa's mines, much of this movement has ended. Although the conditions under which miners served during the apartheid period were justifiably criticized, the loss of this avenue for work has proved problematic in some of the surrounding states. Meanwhile irregular immigration of low-skilled workers and of those seeking asylum (from Africa and beyond) has exploded and xenophobia has risen markedly in South Africa, where unemployment levels are deplorable. Jonathan's account also brings out the transition from encouraging European immigration to emigration of 
many of the highly skilled, and he is critical of the government's attempts to address this through manpower planning in immigration policy.

The effect of immigration on wages in the destination countries has been the subject of copious research. The effect of emigration on wages in the countries of origin has not. Yet, as Prachi Mishra points out in her chapter on the subject, emigrants form a much larger fraction of the population in many countries of origin than is typical of per capita immigration rates. Prachi goes on to review the various approaches that have been adopted in an effort to examine this emigrant impact on home wages, as well as the methodological and data issues inherent in such an effort. The hunt for a negative effect of immigration on wages of prior residents has certainly been protracted and not always rewarded. In contrast, Prachi's review of the more limited evidence on emigrants' effects on wages of those left at home is surprisingly uniform: emigration results in significant and substantial wage escalation at home. Prachi puts this in context for us by considering some of the distributional consequences of these effects as well as some of the net welfare impacts. This rather neglected topic appears important and one might hope that Prachi's chapter will spur and aid further investigation.

Meanwhile, the competition to attract the highly skilled intensifies, with new competitors entering the fray and opportunities to study abroad expanding. The term 'brain-drain' may have been coined by the Royal Society in post-World War II Britain. Certainly, the extent of 'brain-drain' from the developing regions is growing and remains a common cause of concern in the home countries. Yet, more recently, economists have turned their attention to several mechanisms through which emigration of the highly skilled may actually promote development at home, resulting in offsetting 'brain gain'. In addition to remittances transferred by the highly skilled diaspora, at least four mechanisms of potential brain gain have been discussed: induced education among those remaining at home; the transfer of technology to the home country; promotion of bilateral trade as a result of bilateral migration; and through the influences of returned emigrants.

Olena Ivus and Alireza Naghavi address that part of the brain-gain argument dealing with the role of migrants in transferring technology. Specifically, Olena and Alireza survey three sets of literature: the theoretical and empirical modeling, over the last decade and a half, on the international diffusion of technology and its contribution to growth; the investigations, usually as case studies, into technology transfers enabled by migrants; and third, studies of the influence of the diaspora on institutions at home, including the evolution of democracy, and the incidence of rentseeking and expropriation. The first of these sets has been more concerned 
with investigating the magnitudes of technology transfers and their effects, typically through analysis of patent registrations, rather than investigating the mechanisms of transfer. Such means of transfer may include technology conveyed as a result of direct investments, either within the firm or through learning by others; it may simply involve reverse engineering; but it clearly may also involve the movements of scientists and engineers. In light of this, Olena and Alireza explore the potential for linking the literatures on the extent of technology transfers and on diaspora transfers literatures that have not really been integrated. Drawing on prior work by Alireza (with Chiara Strozzi), this chapter demonstrates that emigration and innovation at home are positively correlated when the institutional structure at home offers significant protection to intellectual property rights. In other words, emigration, technology transfer and institutional development all interact in important ways: emigration promotes knowledge transfer while enabling the institutional development necessary to make such transfers effective.

In my own chapter, I present fresh evidence on the empirical links between bilateral migration and trade, with particular emphasis on the case of lower-income countries, which have been omitted from most of the prior analyses. Comparisons are drawn with findings from the extensive literature on this link, which is surveyed by Chris Parsons and Alan Winters in their chapter. In fact, there is little agreement among prior studies, except for a positive association between migration and trade. The fresh findings include positive emigrant and immigrant links with trade in all four pairings of lower-income and higher-income countries, including South-South trade. In contrast to prior findings, it is estimated that the elasticity of this association increases with the level of migration over substantial ranges. The elasticity is also shown to be highest for the highly educated (at least among OECD immigrants), higher for females than males and positive for refugees who have fled from one lower-income country to another. The links prove weaker where the trade partners have a common language or colonial heritage, suggesting a role for migrants in overcoming lack of familiarity and associated incomplete information. Reduction in such barriers promotes openness to trade with a gain in efficiency, but the two-way effects offset, such that the balance of trade for lower-income countries may actually deteriorate. Network effects of thirdcountry nationals are also explored and extended to include mutual emigration to third countries, which is estimated to result in trade diversion.

Jackline Wahba's chapter addresses the economics of return migration, its causes and consequences. This is a topic on which the data are especially scant, yet Jackie manages to show that the extent of return migration is far from negligible, while outlining the methodological difficulties 
in defining and measuring return rates. Advances have been made on both theoretical and empirical fronts with respect to the determinants of return migration, and are reviewed in this chapter. In examining the influences of returned migrants on economic development in their home countries, Jackie first lays out the complexities and need to correct for double selection: selection in who migrates and selection in who returns. Nonetheless a burgeoning empirical literature exists, and Jackie summarizes the findings, looking at the contribution of return migration in reducing credit constraints, allowing for brain circulation and gains, and transmitting of norms to sending economies.

Whereas the brain drain is almost entirely to the high-income countries, especially to the USA, only a very select set of refugees manages to be resettled in these high-income countries. The vast majority of the 10.4 million refugees of concern to UNHCR at the beginning of 2013 not only originated from developing countries but received asylum in neighboring developing countries. While the numbers of armed conflicts in the world and of recognized refugees escaping these conflicts have both declined in recent years, the number of internally displaced persons has risen, again especially within the developing countries, as crossing borders has become increasingly difficult. Traditionally, economists have shied away from consideration of these elements of forced migration, perhaps in large part because the term 'forced' suggests compulsion with no room for choice. More recently, as Ana María Ibáñez shows in her chapter, this perception has begun to change. Specifically, Ana María discusses three main elements of choice with respect to displacement in the face of conflict and violence, summarizing the evidence with respect to each. First is the deliberate choice of armed groups to target civilian groups with the intent to cause displacement. Second are household decisions to move in an attempt to escape conflict or violence, decisions in which more traditional determinants of migration are shown to play a role alongside the violence itself, drawing upon both cross-country and micro-level evidence. Third are the decisions among the displaced to return to their homes. This is a nascent field for economists, though less so for other social sciences, and Ana María lays out some thoughts on future directions for research, including integrating economics with other disciplines.

Given the selectivity with respect to who becomes displaced and to where, Florence Kondylis and Valerie Mueller address the problem of identifying the longer-run consequences of displacement and return, in the context of both conflict and of natural disasters. Florence and Valerie note the dearth of evidence on this subject in the context of developing countries, where most of the incidents actually occur. After reviewing such evidence as does exist and laying out a conceptual framework to 
tackle the several methodological issues arising in the identification of displacement as a causal effect, Florence and Valerie go on to present fresh evidence on those displaced by the 1992-95 conflict in BosniaHerzegovina and by the 2011 floods in Pakistan. Their evidence with respect to education, labor-market outcomes and asset holdings points to effects on the displaced that may stretch not just for long periods but even over generations. Given these important impacts, Florence and Valerie close their chapter with a consideration of potential policy strategies to ameliorate these shocks.

The rise in international terrorism has brought security concerns to the forefront of border control and migrant screening for many countries. In the final chapter in this volume, Pınar Derin-Güre summarizes three main aspects of the literature on development-migration-terrorism links: the economic roots of terrorist acts; the macroeconomic effects of terrorist incidents on the target countries; and analyses exploring the direct connections between immigration and terrorism. The last set of these finds that, although the majority of international terrorist attacks are carried out by immigrants, countries that are more open to immigration have not been subjected to more incidents. Where incidents occur, the macroeconomic effects in terms of a number of indicators have been shown to be negative, at least in the short run, though more work may be called for in looking at the longer-term consequences. The focus of Pinar's contribution is, however, on the economic roots of terrorism. Despite a common perception that poverty exacerbates terrorist tendencies, the bulk of the prior evidence finds little or no such association. However, using a very rich, bilateral, panel data set on the countries of terrorists' origin and target countries, Pinar is able to demonstrate that rising incomes within the average country are associated with diminished terrorism stemming from there.

Taken together, the contributions in this volume summarize and extend the state of thinking and evidence on some of the less well-trodden paths linking international migration and development: the coherence of tradeaid-migration strategies of the wealthier nations, the direction of effect of development on migration, the implications of temporary migration schemes and movements of less-skilled workers, elements of potential brain gain distilled from the diaspora and returned migrants, and the economic roots and consequences of forced migration and of international terrorism. Much remains to be done both in this range of topics and others besides. As the data on international migration become steadily richer, such extensions will be rendered increasingly feasible. It is to be hoped that the reviews and thoughts on future work offered here may help in shaping those future directions. 